СПИСАНИЕ НА БЪЛГАРСКОТО ГЕОЛОГИЧЕСКО ДРУЖЕСТВО, год. 82, кн. 3, 2021, с. 99-101

REVIEW OF THE BULGARIAN GEOLOGICAL SOCIETY, vol. 82, part 3, 2021, p. 99-101

\title{
Are there Pre-Variscan bedded cherts of endogenous origin in Bulgaria?
}

\section{Има ли в България превариски лидити с ендогенен произход?}

\author{
Iliana Boncheva ${ }^{1}$, Valeri Sachanski ${ }^{1,2}$, Polina Andreeva ${ }^{1}$, Tanya Stoylkova ${ }^{3}$, Milena Georgieva ${ }^{3}$ \\ Илияна Бончева ${ }^{1}$, Валери Сачански ${ }^{1,2}$, Полина Андреева ${ }^{1}$, Таня Стоилкова ${ }^{3}$, Милена Георгиева \\ ${ }^{1}$ Geological Institute, Bulgarian Academy of Sciences, Acad. G. Bonchev Str., Bl. 24, 1113 Sofia; \\ E-mails: boncheva2005@yahoo.com; v_sachanski@geology.bas.bg; poly_a@abv.bg \\ ${ }^{2}$ University of Mining and Geology, Studentski Grad, Prof. Boyan Kamenov Str., 1700 Sofia; E-mail: valeri.sachanski@mgu.bg \\ ${ }^{3}$ Sofia University “St Kliment Ohridski”, 15 Tsar Osvoboditel Blvd., 1504 Sofia; E-mails: tstoilkova@gea.uni-sofia.bg; \\ milena@gea.uni-sofia.bg
}

\begin{abstract}
Geochemical studies of different Paleozoic intervals composed of bedded cherts, revealed in the western parts of the Srednogorie and Morava-Rhodope zones are presented: Saltar Fm; the lower and middle part of Katina Fm; the lowest part of Parchar Fm, and Tumba Fm. To determine whether the different bedded cherts intervals are hydrothermally affected, triangular diagrams of the A-F-Mn ratio were used. The low content of Fe compared to Al gives grounds to claim that the Pre-Varisian Paleozoic bedded cherts in Bulgaria are not associated with endogenous processes.
\end{abstract}

Keywords: bedded cherts, Paleozoic, Western Bulgaria.

Лидитите (силицити) са много дребнозърнести непорести седиментни скали, които се състоят предимно или изцяло от $\mathrm{SiO}_{2}$, под формата на аморфен $\mathrm{SiO}_{2}$ или микрокристален кварц, вероятно получен от прекристализация на аморфния $\mathrm{SiO}_{2}$ (Boggs, 2012). Що се отнася до източника на $\mathrm{SiO}_{2}$, за първичен източник се приема биогенният $\mathrm{SiO}_{2}$ - останки от радиоларии, скелетни спикули на гъби, диатомеи. Вулканогенният $\mathrm{SiO}_{2}$, свързан с подводен вулканизъм, може да бъде спомагателен източник (Amichi et al., 1986). Предмет на изследването са палеозойски лидитни последователности, разкриващи се в западните части на Средногорската и МоравскоРодопската зона (Dabovski, Zagorchev, 2009).

Най-старата палеозойска лидитна последователност е формирана веднага след хирнантското заледяване на Гондвана. Разкрива се в Свогенската единица. Нейната дебелина е около $30 \mathrm{~m}$. Изградена е от лидити и аргилити, като лидитите преобладават в първите 10-15 m. Присъствието на лидити е дало основание тази част от разреза да се номинира за официална литостратиграфска единица - Салтарска свита (Sachanski,
Tenchov, 1993). Стратиграфската ѝ позиция е от горен Хирнант до среден Телич (Metabolograptus persculptus-Torquigraptus tullbergi граптолитни зони). Изследван е образец Sv1 от най-долната част на свитата (Parakidograptus ascensus граптолитна зона) в Салтарски дол при с. Батулия. Следващите два лидитни интервала в Свогенската единица са свързани с флишката Кьтинска свита (Tenčov, 1965). Пьрвият е в основата на свитата и е с дебелина около $40 \mathrm{~m}$ (образец $\mathrm{Sv} 2)$. Вторият интервал е с дебелина около $30 \mathrm{~m}$ и се разкрива на около $150 \mathrm{~m}$ над първия (образец Sv3). За тяхната възраст може да се каже само, че са след Емс и преди горен Фран (Boncheva, Yanev, 1993; Lakova in Yanev et al., 2005; Angelov et al., 2010). Опробван е разрезът при с. Царичина.

Отново с флишки седименти са свързани лидитните последователности, разкриващи се в Любашко-Голобърдската единица. Подобно на лидитите в Свогенската единица и тук има два интервала. Първият лидитен пакет (образец $\mathrm{Kr} 2$ ) също е непосредствено преди първите пясъчници на флишката (пре-флишка) Пърчарска свита 
(Yanev, 1985; Yanev, Spasov, 1985). Неговата дебелина е около $5 \mathrm{~m}$. Разполага се над черни аргилити с лохковски граптолити (Yanev, Spasov, 1985; Sachanski, 2017). Вторият интервал (образец $\mathrm{Kr} 3$ ) е значително по-дебел и е отделен като официална литостратиграфска единица - Тумбешка свита (Yanev, Spasov, 1985). Основание за нейното отделянето е наличието на лидити в нея, които алтернират с аргилити, алевролити и пясъчници. Според Янев \& Спасов (Yanev, Spasov, 1985) дебелината на свитата рядко надминава 170-250 m, като на места по-чистите лидитни пакети обхващат 45-50 m. Възрастта на тази свита вероятно е фаменска (Yanev, Spasov, 1985), post-Annulatta event (Boncheva et al., 2015). Опробван е разрезът при с. Станьовци.

В алохтонната Моравска единица са изследвани лидити от Пенкьовския навлак при с. Еловица (образец $\mathrm{Kr} 4$ ), асоцииращи с карбонатни скали, които Маринова и др. (Marinova et al., 2010) отнасят към долнодевонската Врабчанска свита (Spasov, 1973). Използването на литостратиграфската подялба, предложена от Спасов (Spasov, 1973) за интензивно деформираните скали в навлаците от Моравската единица, е неудачно (Boncheva, Sachanski, 2016). За тези структури е по-подходящо да се използва Косовска свита (Parvanov, 1967; Zagorchev, 2001) или Косовски метаседименти (Milovanov et al., 2006), като се отделят карбонатните нива. Тези нива имат различна възраст (Долен Девон, Горен Девон, Карбон) и отнасянето им към Врабчанската свита (Долен Девон) е неуместно. Предложената от Spasov (1973) подялба е използваема за клипите на Пенкьовския навлак. Един добре издържан лидитен интервал е установен в Здравковата свита (Spasov, 1973). Той е опробван във Вонската клипа при с. Мурено (образец Kr1).

Yanev (1991a) предполага, че част от палеозойските лидити имат ендогенен произход и са свързани с хидротермално подхранване със $\mathrm{SiO}_{2}$ (нива Sv3, Kr1 и $\mathrm{Kr} 3$ ).

В настоящото изследване, за да се определи дали различните лидитни интервали са хидротермално повлияни, са използвани триъгълна диаграма за съотношението Al-Fe-Mn (Adachi et al., 1986). Резултатите от химичния анализ на главни оксиди са дадени в табл. 1. Анализите са направени в Лабораторията за химичен анализ на геоложки материали на Софийски университет чрез EDXRF Epsilon 3XLE, Omnian 3. Измерванията са реализирани в стопилки със състав $1 \mathrm{~g}$ проба : 3 g LiBO $_{2}: 6 \mathrm{~g} \mathrm{Li}_{2} \mathrm{~B}_{4} \mathrm{O}_{7}$. Съотношението $\mathrm{Al}-\mathrm{Fe}-\mathrm{Mn}$ за седемте проби е показано на фиг. 1a, $1-7$. Тъй като съдържанията на манган са много ниски, анализите се разполагат близо до $\mathrm{Al}-\mathrm{Fe}$ страната на триъгълника. Няма резултат, който
Таблица 1. Химични анализи на лидитните интервали (wt\%)

\begin{tabular}{lrrrrrrr}
\hline Ниво & \multicolumn{1}{c}{$\mathrm{Sv1}$} & $\mathrm{Sv} 2$ & $\mathrm{~Sv} 3$ & $\mathrm{Kr} 1$ & $\mathrm{Kr} 2$ & $\mathrm{Kr} 3$ & $\mathrm{Kr} 4$ \\
\hline Фиг. 1a & \multicolumn{1}{c}{1} & \multicolumn{1}{c}{2} & \multicolumn{1}{c}{3} & \multicolumn{1}{c}{4} & \multicolumn{1}{c}{5} & \multicolumn{1}{c}{6} & \multicolumn{1}{c}{7} \\
\hline $\mathrm{SiO}_{2}$ & 89,86 & 78,04 & 92,90 & 91,01 & 90,81 & 76,06 & 96,09 \\
$\mathrm{TiO}_{2}$ & 0,20 & 0,41 & 0,12 & 0,15 & 0,14 & 0,49 & 0,08 \\
$\mathrm{Al}_{2} \mathrm{O}_{3}$ & 4,48 & 8,72 & 3,34 & 3,41 & 3,79 & 10,92 & 1,95 \\
$\mathrm{Fe}_{2} \mathrm{O}_{3}$ & 0,15 & 2,73 & 0,07 & 0,88 & 1,80 & 3,29 & 0,04 \\
$\mathrm{FeO}$ & 0,56 & 2,80 & 0,32 & 0,38 & 0,30 & 1,43 & 0,27 \\
$\mathrm{MgO}$ & 0,21 & 2,11 & 0,13 & 0,20 & 0,37 & 1,31 & 0,11 \\
$\mathrm{MnO}$ & 0,00 & 0,13 & 0,00 & 0,04 & 0,01 & 0,11 & 0,00 \\
$\mathrm{CaO}$ & 0,01 & 0,08 & 0,03 & 1,11 & 0,07 & 0,09 & 0,03 \\
$\mathrm{~K}_{2} \mathrm{O}$ & 0,89 & 1,15 & 0,59 & 0,60 & 0,67 & 1,85 & 0,32 \\
$\mathrm{Na} \mathrm{O}_{2}$ & 0,28 & 0,38 & 0,10 & 0,16 & 0,04 & 0,36 & 0,02 \\
$\mathrm{P}_{2} \mathrm{O}_{5}$ & 0,02 & 0,02 & 0,02 & 0,63 & 0,04 & 0,04 & 0,01 \\
$\mathrm{LOI}$ & 3,27 & 3,11 & 2,34 & 1,39 & 1,93 & 3,87 & 1,05 \\
Сума & 99,94 & 99,69 & 99,96 & 99,95 & 99,96 & 99,82 & 99,97 \\
\hline
\end{tabular}

да попада в полето на хидротермалните лидити. Четири от пробите (Sv2, Kr1, Kr2 и Kr3) попадат в полето на нехидротермалните лидити, докато при останалите три (Sv1, Sv3 и Kr4) отношението $\mathrm{Al} / \mathrm{Fe}$ е над 4 и тези образци попадат над полето на нехидротермалните лидити, близо до върха на алуминия.

Химическият състав на различни палеозойски интервали, изградени от лидити, дава Спасов (Spasov, 1960a, b). Те се отнасят до ландоверските лидити в Свогенската единица (ниво Sv1 в настоящото изследване, фиг. $1 \mathrm{~b}, 8-11)$ и до лидитните интервали от основата и средната част на девонския флиш в Любашко-Голобърдската единица (съответно нива $\mathrm{Kr} 2$ и $\mathrm{Kr} 3$, фиг. $1 \mathrm{~b}$, 12 и 13). Последните две са публикувани и от Yanev (1985). Нанесени на Al-Fe-Mn диаграма, четири от тях попадат в полето на нехидротер-

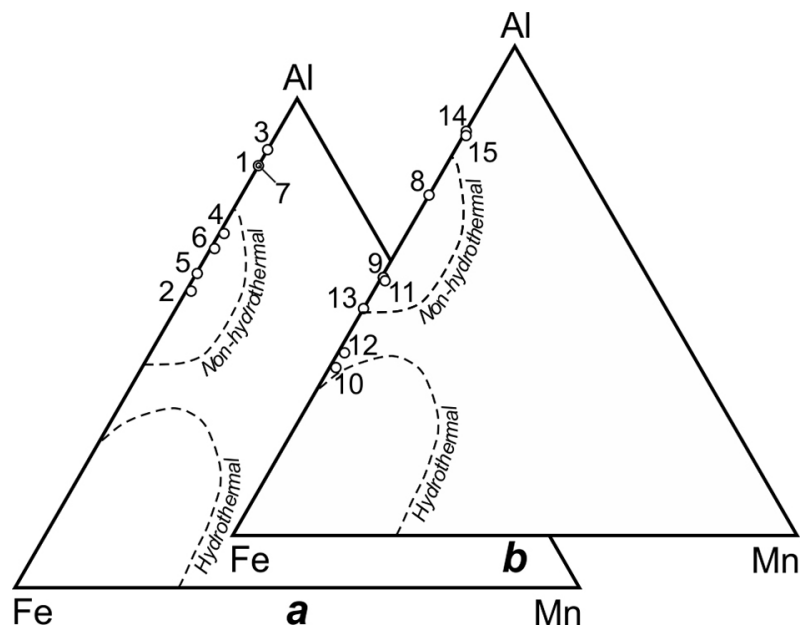

Фиг. 1. Лидити, изследвани в настоящата работа (a) и изследвани от Spasov (1960a, b) и Yanev et al. (2003) (b), нанесени на Al-Fe-Mn диаграма (по Adachi et al., 1986) с полета на хидротермални и нехидротермални лидити 
малните лидити, а две са между двете полета (фиг. 1b). Публикувани са (Yanev et al., 2003) средноаритметичните съдържания на лидитната задруга в Свогенската антиклинала (ниво Sv1 в настоящото изследване, фиг. 1b, 14) и на лидитно-аргилитната алтернация при с. Еловица (ниво Kr4 в настоящото изследване, фиг. 1b, 15), като и двете попадат над полето на нехидротермалните лидити. В други статии (Yanev, 1991b, 1992) са публикувани геохимични данни за палеозойски лидити от България, но резултатите са дадени в някакъв интервал (от-до), което не позволява прилагането на този анализ.

Ниското съдържание на желязо спрямо алуминий дава основание да се твърди, че превариските палеозойски лидити в България не са свързани с ендогенни процеси.

Благодарности: Настоящото изследване е проведено във връзка с изпълнението на Национална научна програма (ННП) ,Опазване на околната среда и намаляване на риска от неблагоприятни явления и природни бедствия“, одобрена с Решение на МС № 577/17.08.2018 г. и финансирана от МОН (Споразумение № Д01363/17.12.2020).

\section{Литература References}

Adachi, M., K. Yamamoto, R. Sugisaki. 1986. Hydrothermal chert and associated siliceous rocks from the northern Pacific: their geological significance and indication of ocean ridge activity. - Sedim. Geol., 47, 125-148; https://doi. org/10.1016/0037-0738(86)90075-8.

Angelov, V., V. Sachanski, S. Tanatsiev. 2010. Ogradishte and Romcha Formation - new lithostratigraphic units for the Upper Silurian and Devonian sediments in the Svoge tectonic unit. - Rev. Bulg. Geol. Soc., 71, 1-3, 5-15 (in Bulgarian with English abstract).

Boggs, S. jr. 2012. Evaporites, cherts, iron-rich sedimentary rocks, and phosphorites. - In: Boggs, S., jr. (Ed.). Petrology of Sedimentary Rocks. Cambridge University Press, 461526; https://doi.org/10.1017/CBO9780511626487.013.

Boncheva, I., V. Sachanski. 2016. New data on the age of the rocks of Rizovtsi allochthone (Moravian Unit) at Stradalovo village, Kyustendil district. - Rev. Bulg. Geol. Soc., 77, 1, 19-25 (in Bulgarian, with English abstract).

Boncheva, I., S. Yanev. 1993. New data on the Paleozoic flysch of the Sofiyska Stara Planina Mountain. - Geologica Balc., $23,5,15-22$.

Boncheva, I., V. Sachanski, R. T. Becker. 2015. Late Devonian Kellwasser and Annulata events in the Balkan Terrane (Bulgaria). - Geologica Balc., 44, 1-3, 17-24.

Dabovski, H., I. Zagorchev. 2009. Alpine tectonic subdivision of Bulgaria. - In: Zagorchev, I., H. Dabovski, T. Nikolov
(Eds). Geology of Bulgaria. Vol. II. Part 5. Mesozoic Geology. Sofia, Prof. Marin Drinov Publishing House, Bulg. Acad. Sci., 30-37 (in Bulgarian with English abstract).

Marinova, R., V. Grozdev, D. Ivanova, D. Sinnyovsky, P. Milovanov, I. Petrov, A. Popov. 2010. Geological Map of the Republic of Bulgaria $n$ Scale 1:50 000. K-34-45-B (Tsravena Yabuka), K-34-45-G (Vlasotintse), K-34-46-A (TranNorth), K-34-46-V (Tran-South) Map Sheets. Ministry of Environment and Water, Bulgarian National Geological Survey.

Milovanov, P., E. Goranov, V. Zhelev, V. Valev, I. Petrov, E Ilieva. 2006. Explanatory Nnote to the Geological Map of the Republic of Bulgaria 1:50 000, K-34-57-B (Bosilegrad) and K-34-58-A (Treklyano) Map Sheets. Sofia, Ministry of Environment and Water, Bulgarian Geological Survey, 59 p.

Parvanov, B. 1967. Attempt for a stratigraphic subdivision of the metamorphic rocks in the central and southern part of the Kraishte. - In: Jubilee Volume on Geology, Sofia, Committee of Geology, 317-323 (in Bulgarian).

Sachanski, V., Y. Tenchov. 1993. Lithostratigraphic subdivision of the Silurian sediments in the Svoge anticline. - Rev. Bulg. Geol. Soc., 54, 1, 71-81 (in Bulgarian with English abstract).

Spasov, C. 1960a. Stratigraphie der paläozoische Sedimente zwischen Tran und Temelkovo in Südwestbulgarien. Travaux sur la Géologie de Bulgarie, Serie Stratigraphie et Tectonique, 1, 93-102 (in Bulgarian with Russian and German abstracts).

Spasov, C. 1960b. Stratigraphie des Ordoviziums und Silurs im Kern der Svoge-Antiklinale. - Travaux sur la Géologie de Bulgarie, Serie Stratigraphie et Tectonique, 1, 161-202 (in Bulgarian with Russian and German abstracts).

Spasov, H. 1973. Stratigraphy of the Devonian in SW Bulgaria.Bull. Geol. Inst., Sofia, Ser. Stratigr. and Lithology, 22, 5-38 (in Bulgarian with Russian and German abstracts).

Tenčov, J. 1965. Ober Devon im Kern der Svoge-Antikline. Rev. Bulg. Geol. Soc., 26, 1, 109-112 (in Bulgarian with German abstract).

Yanev, S. 1985. Devonian flysch in the Černogorie (Sauthwest Bulgaria). - Palaeont., Stratigr., Lithol., 21, 88-97 (in Bulgarian with Russian and English abstracts).

Yanev, S. 1991a. Genetic environments of chert formations in the Paleozoic sections in Bulgaria. - In: Abstracts VI Intern. Flint Symposium. October 1991, Spain, 26-28.

Yanev, S. 1991b. Paleozoic cherts in Bulgaria. - In: Abstracts VI Intern. Flint Symposium. October 1991, Spain, 61-64.

Yanev, S. 1992. Contribution to the elucidation of pre-Alpine evolution in Bulgaria (based on sedimentological data from the marine Paleozoic). - Geologica Balc., 22, 2, 3-31.

Yanev, S., C. Spasov. 1985. Lithostratigraphy of the Devonian flysh between Tran and Temelkovo. - Paleontol., Stratigr., Lithol., 21, 82-86.

Yanev, S., Y. Uzunov, K. Uzunov. 2003. The Paleozoic pelitic rocks in Bulgaria. III. Geochemical study. - Rev. Bulg. Geol. Soc., 64, 1-3, 13-22 (in Bulgarian with English abstract).

Yanev, S., I. Lakova, I. Boncheva, V. Sachanski. 2005. The Moesian and Balkan Terrans in Bulgaria: Palaeozoic marine basin development, palaeogeography and tectonic evolution. - Geologica Belg., 8, 4, 185-192.

Zagorchev, I. 2001. Introduction to the geology of SW Bulgaria. - Geologica Balc., 31, 1-2, 3-52. 